\title{
Efeitos ideológicos entre o verbal e o não-verbal ${ }^{*}$
}

\author{
Daiana Oliveira Faria**
}

Resumo: Sob a ótica da Análise do Discurso (AD) de matriz francesa, observamos os efeitos de sentidos provocados pelo verbal e não-verbal. A partir disso, focamos como se dá, nessa materialidade, o processo de interpelação ideológica. Para tanto, selecionamos como corpus um infográfico publicado numa edição especial da revista SuperInteressante sobre Che Guevara, edição de número 261. É diante dos efeitos de sentidos provocados por esse fato histórico, condensado na materialidade do infográfico, que tecemos nossas análises.

Palavras-chave: discurso; ideologia; Che Guevara.

\section{Ideologia e Discurso}

Ao longo de nossos estudos sobre o funcionamento discursivo da/na rede eletrônica, chama nossa atenção os aspectos ideológicos postos na teia do discurso e, por isso, somos levadas a refletir sobre os conceitos de formação discursiva (FD), formação social (FS) e formação ideológica (FI). Ressaltamos que eles possuem uma relação mais estreita com o modo como Michel Pêcheux desdobrou seus estudos sobre ideologia. A própria noção de discurso, que é o observatório da AD, seu objeto de estudo, compreende os dizeres imbricados pelos aspectos sociais, históricos e ideológicos. Isso posto, recorremos às palavras de Pêcheux, quando da explanação sobre o que a ideologia evoca, quando pensada no âmbito da AD:

É pois teoricamente impossível considerar a ideologia como uma "consciência de grupo", uma representação de mundo, um bloco de idéias válidas para uma sociedade ou uma classe, e que tenderia a se impor como um "todo" que o funcionalismo poderia apreender (PÊCHEUX, 1995 [1969], p. 82).

\section{Corpus de análise}

Mais que visão de mundo, ideologia em $\mathrm{AD}$ pode ser resumida enquanto mecanismo que promove efeito de evidência nos ditos do sujeito. Tal evidência é reafirmada pela inscrição desse sujeito em dada FD, instaurada a partir da FS e FI, as quais esse sujeito está atrelado. Acerca da FI, podemos dizer que se trata do complexo do que pode e deve ser dito dentro de uma posição, ou seja, o que possibilita ao sujeito inscrever-se em uma dada FD e não em outra (PÊCHEUX, 1969). Tendo em vista o processo de interpelação ideológica, podemos pensar a FD enquanto a projeção, na linguagem, ou seja, a materialização lingüística das FI's que determinam o que pode e deve ser dito. Nesse sentido, "as palavras, expressões, recebem seus sentidos da

\footnotetext{
*Esse texto é um recorte do TCC "Informação e discurso: sentidos em movimento" (2009).

** Mestranda na FFCLRP/USP. Bolsista FAPESP. Pesquisadora do E-L@DIS - Laboratório Discursivo: sujeito, rede eletrônica e sentidos em movimento, da FFCLRP/USP. E-mail: daianafaria@pg.ffclrp.usp.br
} 
formação discursiva à qual pertencem" (PÊCHEUX, 1998, p. 263). O funcionamento desses três conceitos - FS, FI e FD - representa a

[...] conversão do indivíduo em sujeito pela interpelação (captura) deste como sujeito de uma formação social, e que se reconhece como sujeito pelas práticas que o interpelam no interior das formações ideológicas, as quais se referendam através de uma ou outra formação discursiva a que estão ligadas (ZANDWAIS, 2009, p. 25).

Passando para o corpus, o infográfico consiste num recurso bastante difundido nos meios de comunicação a fim proporcionar aos leitores dados históricos, estatísticos, geográficos, a partir de imagens e textos rápidos, imaginariamente capazes de dizer muito mobilizando menor volume de palavras. O que já nos mostra a ideologia em funcionamento: ao propor um infográfico e não um texto corrido, presume-se que um número maior de leitores irão acessar este conteúdo, ou seja, dessa forma será mais fácil de apreender o conteúdo, inferindo que uma grande parcela da população não tem o hábito de ler grandes textos e que se relacionam melhor com imagens. Esse efeito de evidência que move os editores da revista é traço ideológico. Até mesmo esse tipo de disposição gráfica utilizado, que remete a jogos de guerra. A característica de um infográfico é dispor textos curtos e figuras, mas a maneira como esse recurso foi manipulado nesta imagem, fez remeter a sentidos bélicos, uma vez que a vista aérea nos mostra um cenário de guerra.

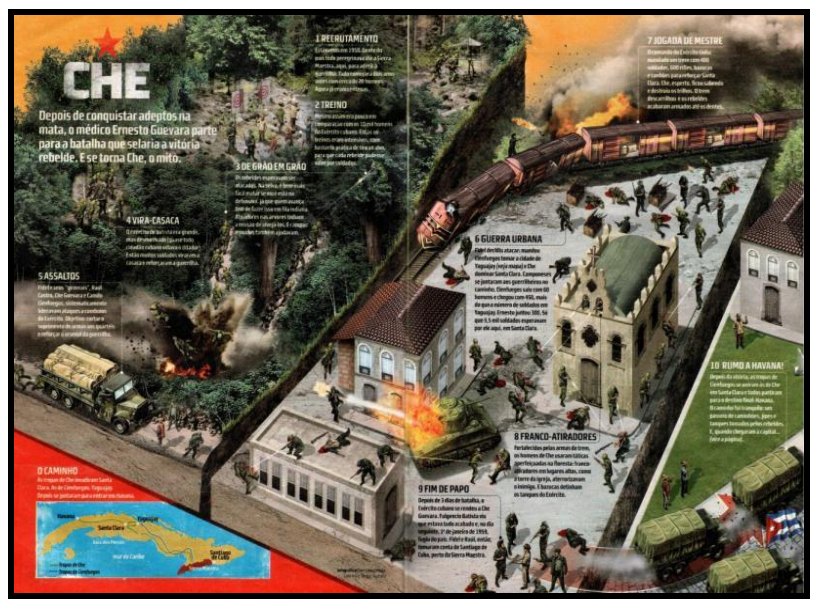

Figura 1 - SUPER INTERESSANTE: A verdade sobre Che. Fonte: Super Interessante. São Paulo: Casa Amarela, n. 261, out.2007, p. 49-50. 
Vejamos a semelhança com os games de guerra:

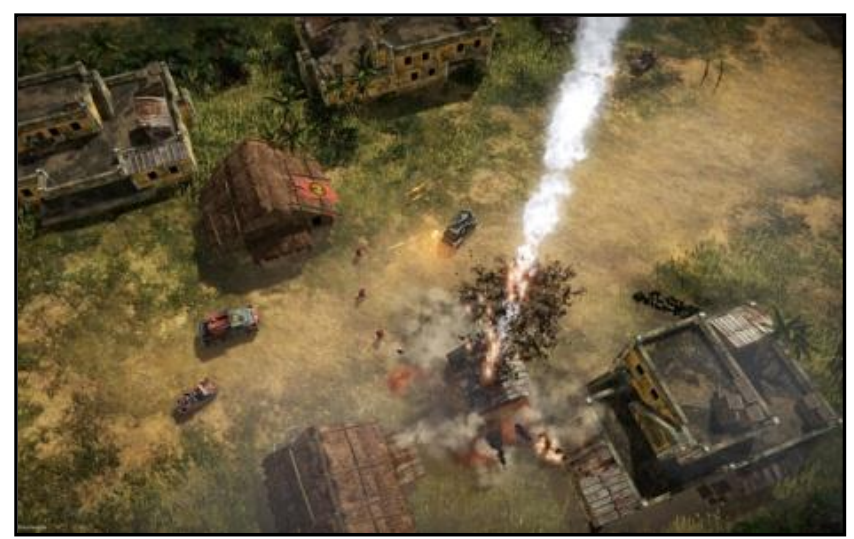

Figura 2 - Renegade Ops (Foto: Divulgação).

E pelo efeito de evidência, sabemos o enredo desses jogos, e são esses os sentidos instaurados para significar tal fato histórico. Vemos o imbricamento de várias materialidades, característica da multimídia: cenário de games eletrônicos; tabuleiro de jogos tradicionais; entre outros, atrelados a textos curtos, o que nos faz pensar os efeitos do verbal e não-verbal: "é assim que a multimídia ganha unidade em sua representação: pelo verbal. Garantia de legibilidade, de interpretação, linguisticamente organizada" (ORLANDI, 1995, p. 43), vendável! Isso vem corroborar com a leitura do traço ideológico que fizemos acima, os efeitos da imagem atraem o leitor que encontram unidade e legibilidade no verbal, mastigado, nesse caso. E como vemos, o verbal reafirma os sentidos bélicos instaurados pelo não-verbal, com o emprego dos significantes: batalha, recrutamento, guerrilha, treino, matar, defensiva, atiradores, campos-minados, exército, generais, etc.

Podemos ver, diante do exposto, como os textos midiáticos são carregados de traços ideológicos estrategicamente manipulados de forma a atingir os objetivos: venda e formação de opinião que virá a corroborar, na maioria das vezes, com o discurso dominante.

\section{Referências}

ORLANDI, Eni P. As formas do silêncio: no movimento dos sentidos. Campinas, SP: Editora da Unicamp, 1995, p. 29-34.

PÊCHEUX, Michel. Semântica e discurso: uma crítica a afirmação do óbvio. 3. ed. Traduzido por Eni Puccinelli Orlandi [et al.]. Campinas, SP: Ed. da Unicamp, 1998. 
. Análise automática do discurso (AAD-69). In: GADET, F.; HAK, T. (orgs.). Por uma análise automática do discurso: uma introdução às obras de Michel Pêcheux. Campinas, SP: Ed. da Unicamp, 1997 [1969]. . (Thomas Herbert). Observações para uma Teoria Geral das Ideologias. Rua, Campinas/SP, n. 1, p. 63-90, nov.1995. Traduzido por Carolina M. R. Zuccolillo; Eni Orlandi; José Horta Nunes. Disponível em: <www.labeurb.unicamp.br/rua/>. Acesso em: 29.ago.2011.

ZANDWAIS, Ana. Perspectivas da análise do discurso fundada por Michel Pêcheux na França: uma retomada de percurso. Cogitare, n. 8, Santa Maria/RS, UFSM, Programa de Pós-Graduação em Letras, 2009. 